\title{
Suitability of Different Observational Lenses for Viewing the Macular Area Through Multifocal Intraocular Lenses in a Model of the Human Eye
}

This article was published in the following Dove Press journal: Clinical Ophthalmology

\section{Tomoyuki Watanabe (iD \\ Akira Watanabe \\ Tadashi Nakano (iD}

Department of Ophthalmology, The Jikei University School of Medicine, Tokyo I05-846I, Japan
Correspondence: Tomoyuki Watanabe Department of Ophthalmology, The Jikei University School of Medicine, 3-25-8

Nishi-Shimbashi, Minato-Ku, Tokyo I05846I, Japan

Tel +8I-3-3433-I III (ext. 358I)

$\mathrm{Fax}+8 \mathrm{I}-3-5378-8828$

Email md06-watanabeto@jikei.ac.jp
Purpose: Multifocal intraocular lenses (IOLs) can potentially affect the intraoperative view of the retina. We investigated the suitability of different lenses for viewing the macular area through two multifocal intraocular lenses in a human eye model.

Methods: This study compared the image quality of graduated index $(0.1 \mathrm{~mm})$ in a model eye when viewed through refractive or diffractive multifocal IOLs with a meniscus or flat contact lens, and a wide field 60 diopter non-contact lens or wide field contact lens (Super Macula $\left.{ }^{(\mathbb{}}\right)$.

Results: Images acquired through the meniscus contact lens or flat contact lens via the central optical zone of the refractive multifocal IOL or the diffractive multifocal IOL were well focused. However, images viewed through these lenses near the center were warped and out of focus. All images viewed through a wide-field 60 diopter non-contact lens at the central optical zone and near the center were slightly out of focus. All images viewed through the Super Macula at the central optical zone and near the center were well focused. Conclusion: A wide field contact lens (Super Macula ${ }^{(B)}$ ) made it possible to obtain clear images of the macular area at multiple focal points through refractive or diffractive multifocal IOLs.

Keywords: multifocal intraocular lenses, vitrectomy, macula

\section{Introduction}

Due to the success in correcting farsighted and nearsighted vision problems with multifocal intraocular lenses (IOLs), an increasing number of patients have received these lenses. ${ }^{1}$ However, multifocal IOLs may cause a decrease in contrast sensitivity, and lead to negative visual outcomes, such as halos and glare. ${ }^{2}$ Additionally, multifocal IOLs can potentially change or impede the ability to achieve a clear intraoperative view of the retina during surgery. ${ }^{3-9}$ Monofocal IOLs permit the use of a wide viewing system for vitrectomy, and a contact lens for macular surgery. ${ }^{10,11}$ Surgeons often require higher magnification for precise surgical operation, such as removal of epiretinal membranes around the macula or internal limiting membrane peeling for macular holes, which can be achieved with magnifying lenses. ${ }^{12}$ Reports also suggest that the epiretinal membrane can be clearly visualized through a wide-field 60 diopter non-contact lens during macular surgery. ${ }^{13}$

In particular, when performing surgery in patients with previous insertion of a diffractive multifocal IOL, the macular images were found to be significantly 
worse than those observed in eyes with insertion of a refractive multifocal IOL. ${ }^{3}$ As a result, when optimal conditions are not present during surgery, the procedure is significantly more difficult, which can lead to concerns regarding both patient safety and postoperative outcomes.

To further investigate these potential problems, this study compared the quality of a graduated index of images with $0.1 \mathrm{~mm}$ intervals in a model eye when viewed through two multifocal IOLs.

\section{Materials and Methods}

This study used a model eye that was constructed based on Gullstrand's model of the human eye. The body of the eye was made of metal, and the axial length was $24.0 \mathrm{~mm}$. The diameter of the pupil was $7.0 \mathrm{~mm}^{3}$ A graduated index with $0.1 \mathrm{~mm}$ intervals was attached to the posterior surface of the model eye at the position of the retina. The scale was fixed so that the mark 50 line was at the center of the fundus. The model eye was then filled with a balanced salt solution. The IOLs compared included a refractive multifocal IOL (PY60MV, AF-1 iSii, HOYA Surgical Optics, Tokyo, Japan), and a diffractive multifocal IOL (ZM900, Tecnis Multifocal, Abbott Medical Optics, Santa Ana, California, USA).

An opening was created in the model eye at a position similar to that used for pars plana vitrectomy, and a 23 gauge, wide angled, endoilluminating light pipe (DORC, Zuidland, The Netherlands) was inserted. Meniscus and flat contact lenses made of quartz glass (HOYA Surgical Optics, Tokyo, Japan), and a wide-field 60 diopter noncontact lens with Resight ${ }^{\circledR}$ (Carl Zeiss Meditec, Tokyo, Japan) or wide-field viewing Super Macula ${ }^{\circledR}$ contact lens (VOLK, Mentor, OH, USA) were used to view the graduated index.

A digital camera was used to take images of the index through a microscope (Lumera T: Carl Zeiss Meditec, Tokyo, Japan). Images taken with the various lenses and the refractive and diffractive multifocal IOLs were compared (Figure 1). The magnification needed for macular surgery was adjusted on a surgical microscope.
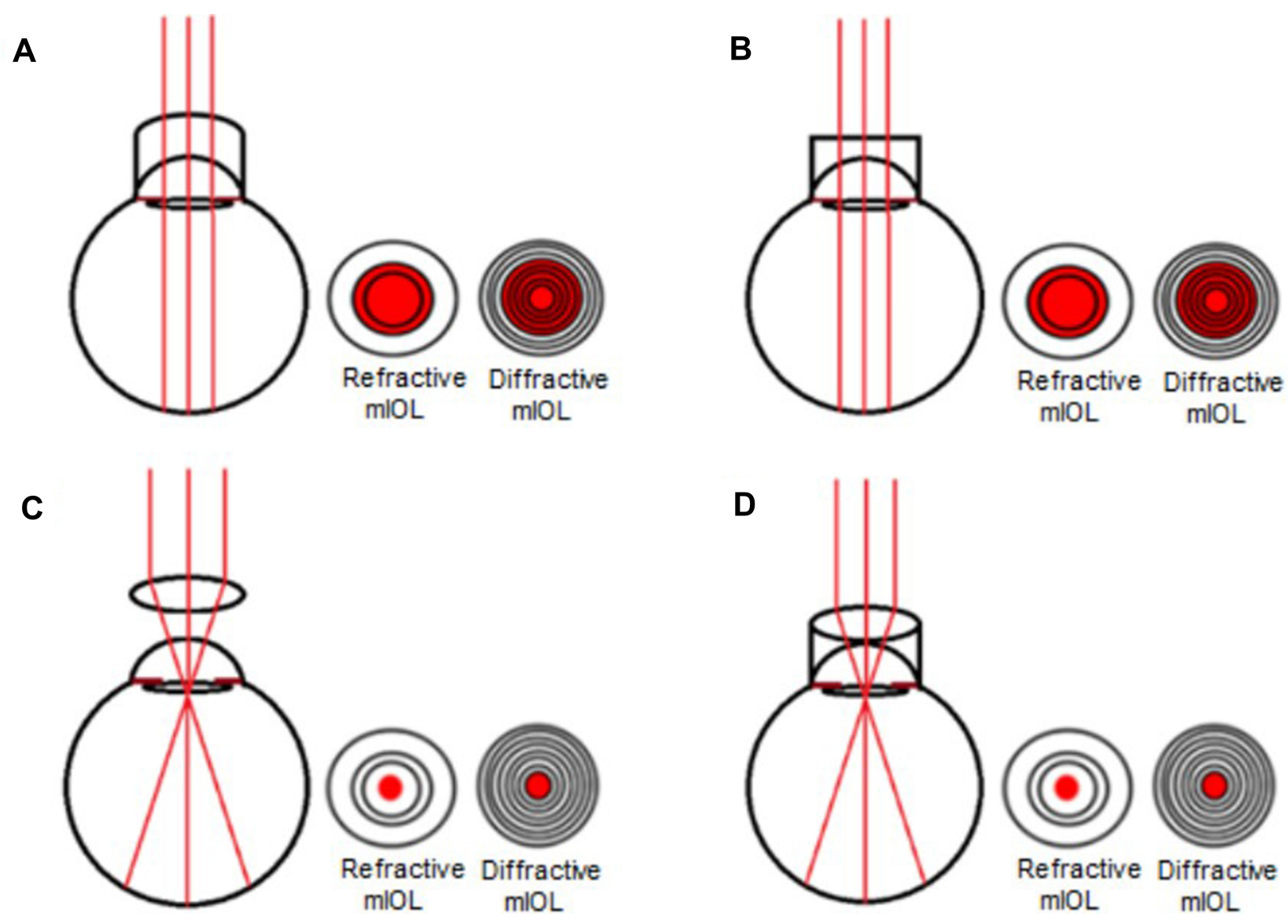

Figure I Path of light with meniscus contact lens, flat contact lens, wide-field 60 diopter non-contact lens and wide field viewing contact lens (Super Macula ${ }^{\circledR}$ ) when using refractive multifocal IOL and diffractive multifocal IOL. (A) Meniscus lens. (B) Flat lens. (C) Wide-field 60 diopter non-contact lens. (D) Wide-field viewing contact lens (Super Macula $\left.{ }^{\circledR}\right)$. 


\section{Results}

All images viewed through the meniscus, flat, and widefield viewing Super Macula ${ }^{\circledR}$ contact lenses via the central optical zone (within $0.3 \mathrm{~mm}$ from the center) of the refractive multifocal PY-60MV were well focused. However, the images obtained for the meniscus and flat contact lenses were warped and out of focus when viewed through the PY-60MV at $0.3-0.5 \mathrm{~mm}$ from the center (Figure 2A and B).

When viewed through the refractive multifocal PY$60 \mathrm{MV}$ and a wide-field 60 diopter non-contact lens, images were out of focus within $0.5 \mathrm{~mm}$ from the center (Figure 2C). In contrast, when viewed through the refractive multifocal PY-60MV with a wide-field viewing Super Macula ${ }^{\circledR}$ contact lens, the image was in good focus at $0.3-0.5 \mathrm{~mm}$ from the center (Figure 2D).

When using the meniscus, flat, and wide-field viewing Super Macula ${ }^{\circledR}$ contact lenses and viewing via the central optical zone (within $0.2 \mathrm{~mm}$ from the center) of the diffractive multifocal ZM900, the images were comparatively well focused. However, when the meniscus and flat lenses caused double images to occur when viewed through the ZM900, with ghost images present at $0.2-0.7 \mathrm{~mm}$ from the center (Figure 3A and B). When the diffractive multifocal ZM900 and wide-field 60 diopter non-contact lens were used, images were out of focus within $0.5 \mathrm{~mm}$ of the center (Figure 3C). Images were well focused at $0.2-0.7 \mathrm{~mm}$ from the center when using a diffractive ZM900 and the wide-field viewing Super Macula ${ }^{\circledR}$ contact lens (Figure 3D).

\section{Discussion}

There are three optical zones for the refractive multifocal PY-60MV. The $2.3 \mathrm{~mm}$ central zone and the third zone are used for far vision, while the second zone is used for near vision. The diffractive multifocal ZM900 use a diffractive design in conjunction with aspheric optics to create sharply focused images of both distant and near objects. It was observed that these lenses reduce visibility of the fundus due to the characteristics of the optics. Previous reports also indicate that the visibility of the fundus of the eye with a multifocal IOL was reduced during vitrectomy. ${ }^{6-9}$
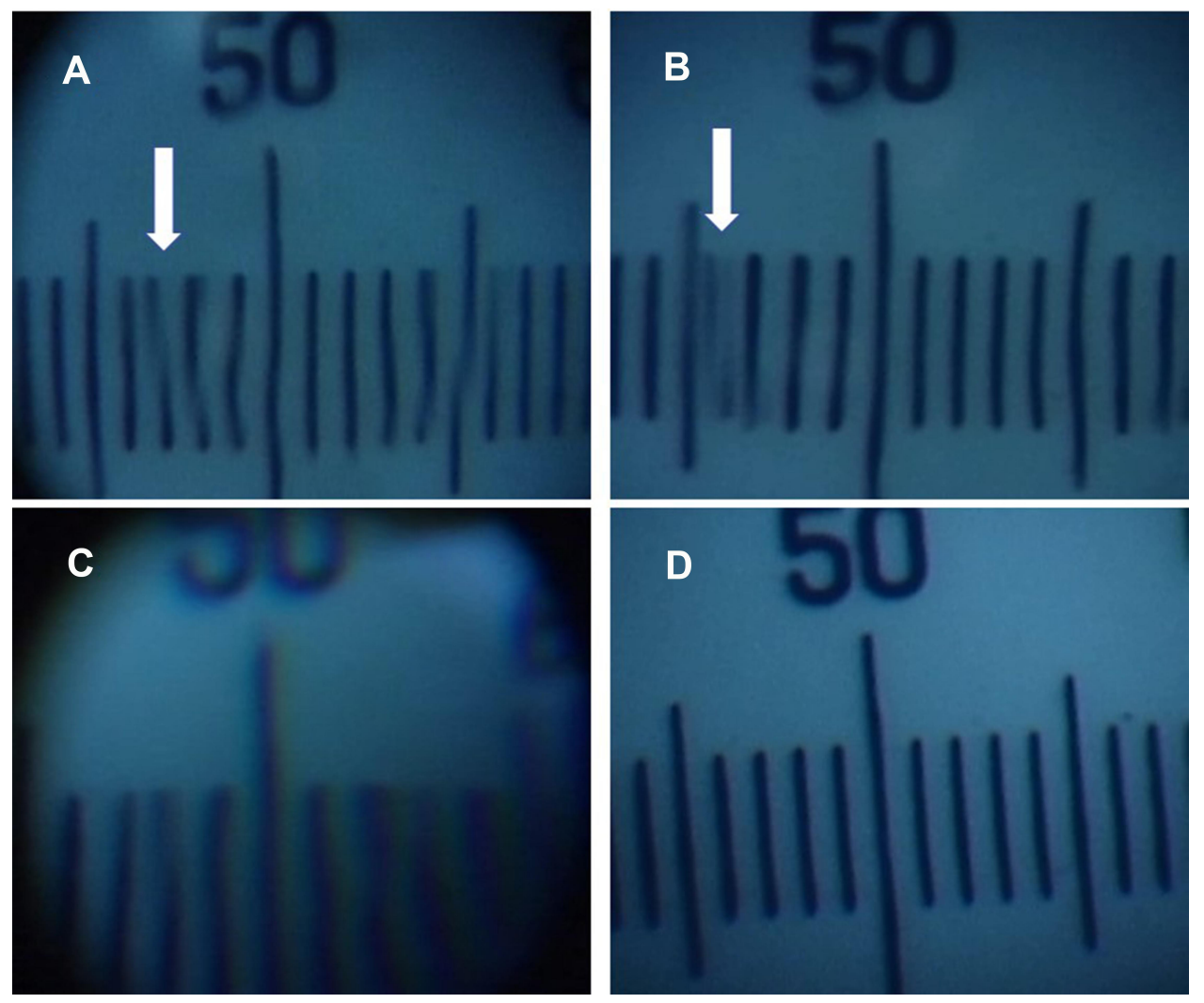

Figure 2 Image of the graduated index in the model eye that was implanted with the refractive multifocal PY-60MV. (A) The index at a distance of $0.3-0.5 \mathrm{~mm}$ from the center is highly warped and out of focus with the meniscus lens. Arrow indicates warped images. (B) The index at a distance of $0.3-0.5 \mathrm{~mm}$ from the center is warped and out of focus with the flat contact lens. Arrow indicates warped images. (C) The index is out of focus with the wide-field 60 diopter non-contact lens using Resight ${ }^{\circledR}$. (D) The index is good focus with the wide-field viewing contact lens (Super Macula ${ }^{\circledR}$ ). 

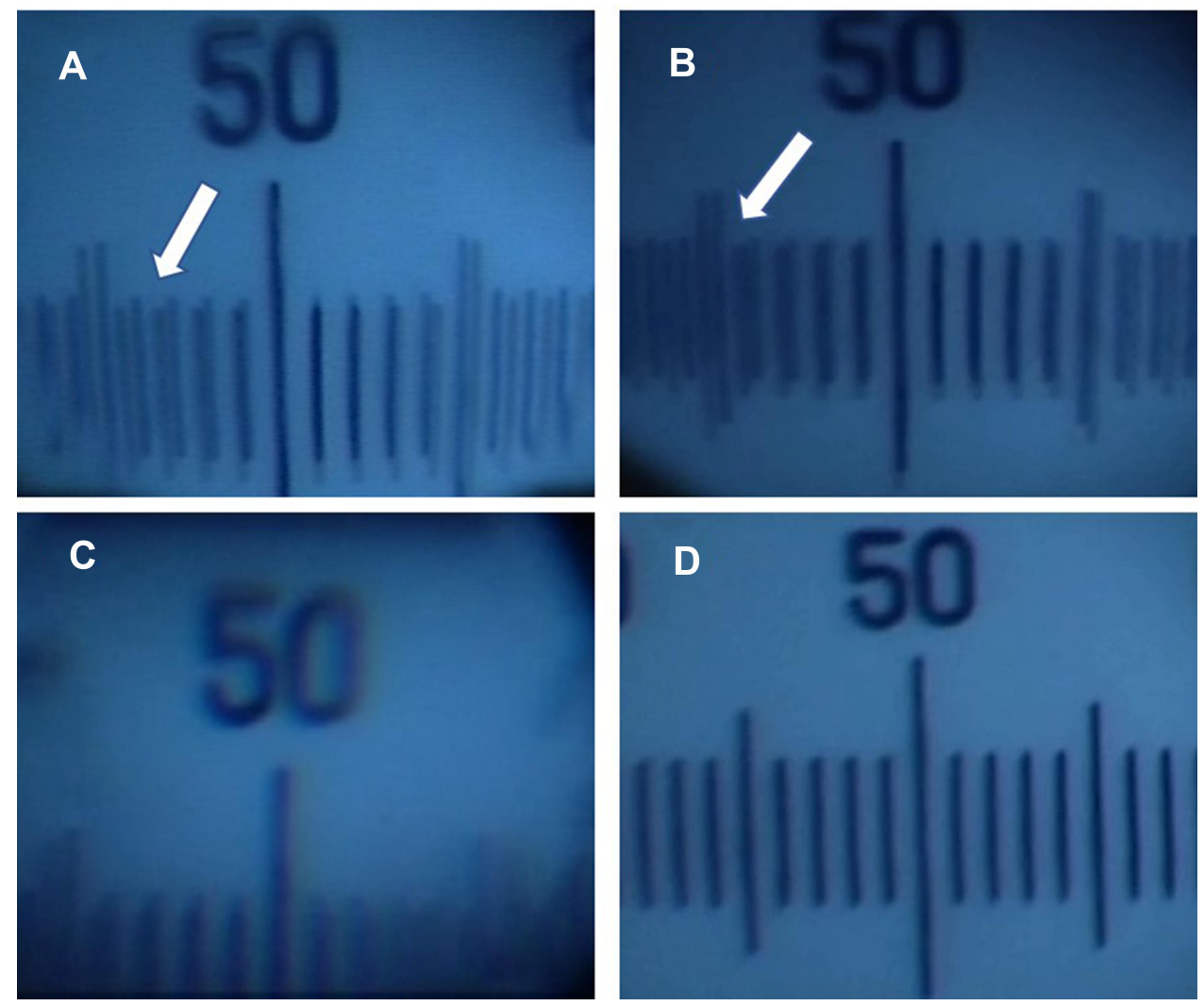

Figure 3 Image of the graduated index in the model eye that was implanted with the diffractive multifocal ZM900. (A) The index at a distance of $0.2-0.7 \mathrm{~mm}$ from the center is seen as double images and ghost images with the meniscus lens. Arrow indicates double images. (B) The index at a distance of $0.2-0.7 \mathrm{~mm}$ from the center is seen as double images and ghost images with the flat contact lens. Arrow indicates double images. (C) The index is out of focus with the wide-field 60 diopter non-contact lens using Resight $^{\circledR}$. (D) The image is in good focus with the wide-field viewing contact lens (Super Macula ${ }^{\circledR}$ ).

The results of this study demonstrated that images could not be clearly observed through the refractive and diffractive multifocal IOLs when using meniscus and flat contact lenses at $0.2-0.7 \mathrm{~mm}$ from the center. Images within $0.2 \mathrm{~mm}$ from the center were clear, but it is more difficult to operate within that distance. Additionally, the wide-field viewing Super Macula ${ }^{\circledR}$ contact lens performed better than wide field 60 diopter noncontact lenses when used with both refractive and diffractive multifocal IOLs.

Our results also showed that Super Macula lenses were not affected by the optical design of the refractive and diffractive multifocal IOLs. This indicates that these IOLs may have contrast sensitivities similar to monofocal IOLs. Additionally, our results suggest that indirect observation systems are less likely to interfere with the refraction and diffraction phenomena of multifocal IOLs (Figure 4).

When focusing the microscope, the central region becomes narrower, especially at high magnifications, meaning that the center of the intraocular lens and the center of the optical axis will shift with a slight movement and the image will be blurred, particularly when using wide-field 60 diopter non-contact lenses.

Another reason that viewing the fundus through a wide-field 60 diopter non-contact lens with a refractive or diffractive multifocal IOL may be blurred is that the non-contact lens is susceptible to aberrations and reflections from the corneal surface, which can result in poor image of resolution and contrast. ${ }^{14-16}$

The Resight ${ }^{\circledR}$ wide-field 128 diopter non-contact lens provides a field of view that is approximately $110^{\circ}$ to $130^{\circ}$ with minification, which our operating microscope was able to magnify. Previous reports indicate that the use of a wide-field viewing contact lens (Mini Quad ${ }^{\circledR}$; Volk Optical, Inc, Mentor, Ohio, USA) in a multifocal IOL inserted eye provides an approximate $106^{\circ}$ to $127^{\circ}$ field of view results in a low magnification. ${ }^{3,16}$ When using these lenses, the image was too wide and therefore was unsuitable for observation of a spot area like macula. 


\section{A (Direct observation system)}

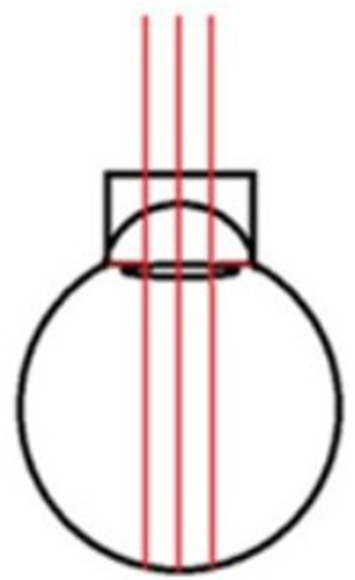

\section{B (Indirect observation system)}

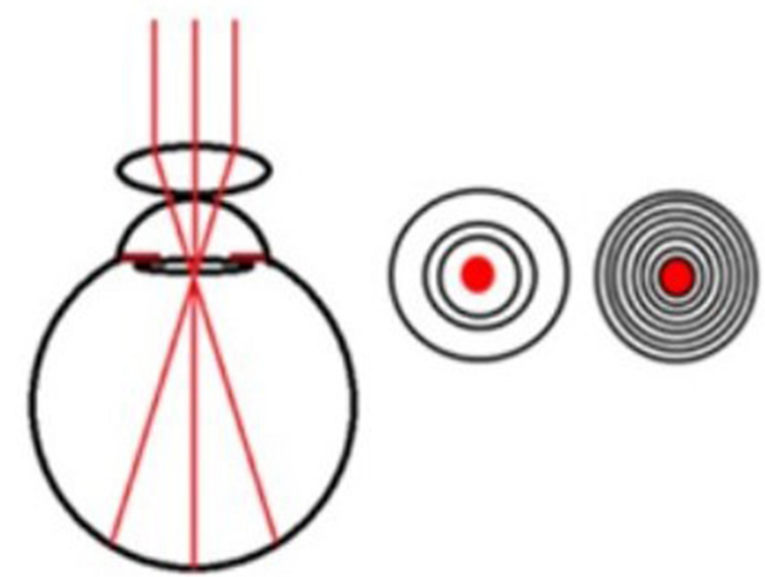

Figure 4 (A) The light parallel to the optic axis does not just pass through the center of the eye with the direct observation system. Thus, when trying to focus the image on the retina, it will be influenced by the refraction and diffraction phenomena, which results in blurring of the image. (B) The light parallel to the optic axis will pass through the center with the indirect observation system. This makes it possible to focus an image on the retina without any influence of the refraction and diffraction phenomena.

\section{Conclusion}

Our study demonstrated that use of wide-field viewing Super Macula ${ }^{\circledR}$ contact lenses, which magnifies the image and provides an approximate $64^{\circ}$ to $77^{\circ}$ field of view, makes it possible to obtain clear images of the macular area through both refractive and diffractive multifocal IOLs.

\section{Author Emails}

md06-watanabeto@jikei.ac.jp (T.W.); akirawa@jikei.ac.jp (A.W.); tnakano@jikei.ac.jp (T.N.).

\section{Funding}

This study was supported by grants from HOYA and AMO.

\section{Disclosure}

The authors declare that there are no conflict of interests regarding this paper.

\section{References}

1. Alio JL, Plaza-Puche AB. Multifocal intraocular lenses: an overview. Surv Ophthalmol. 2017;62:611-634.

2. Kamiya K, Hayashi K, Shimizu K, et al. Multifocal intraocular lens explanation: a case series of 50 eyes. Am J Ophthalmol. 2014;158 (2):215-220. doi:10.1016/j.ajo.2014.04.010
3. Inoue M, Noda T, Mihashi T, et al. Quality of image of grating target placed in model of human eye with corneal aberrations as observed through multifocal intraocular lenses. Am J Ophthalmol. 2011;151 (4):644-652. doi:10.1016/j.ajo.2010.09.029

4. Terwee T, Weeber H, van der Mooren M, et al. Visualization of the retinal image in an eye model with spherical and aspheric, diffractive, and refractive multifocal intraocular lenses. J Refract Surg. 2008;24 (3):223-232. doi:10.3928/1081597X-20080301-03

5. Inoue $\mathrm{M}$, Noda $\mathrm{T}$, Ohnuma $\mathrm{K}$, et al. Quality of image of grating target placed in vitreous of isolated pig eyes photographed through different implanted multifocal intraocular lenses. Acta Ophthalmol. 2011;89(7):e561-e566. doi:10.1111/j.17553768.2011.02173.x

6. Kawamura R, Inoue M, Shinoda $\mathrm{K}$, et al. Intraoperative findings during vitreous surgery after implantation of diffractive multifocal intraocular lens. J Cataract Refract Surg. 2008;34(6):1048-1049. doi:10.1016/j.jcrs.2008.01.031

7. Kumar A, Goyal M, Tewari HK, et al. Posterior segment visualization problems with multifocal intraocular lenses. Acta Ophthalmol Scand. 1996;74(4):415. doi:10.1111/j.1600-0420.1996.tb00722.x

8. Mainster MA, Reichel E, Warren KA, et al. Ophthalmoscopy and vitreoretinal surgery in patients with an ARRAY refractive multifocal intraocular lens implant. Ophthalmic Surg Laser. 2002;33:74-76.

9. Yoshino $\mathrm{M}$, Inoue $\mathrm{M}$, Kitamura $\mathrm{N}$, et al. Diffractive multifocal intraocular lens interferes with intraoperative view. Clin Ophthalmol. 2010;4:467-469.

10. Kunikata H, Nakazawa T. Intraoperative optical coherence tomography-assisted 27-gauge vitrectomy in eyes with vitreoretinal diseases. Case Rep Ophthalmol. 2015;6:216-222.

11. Kunikata H, Abe T, Nakazawa T. Heads-up macular surgery with a 27-gauge microincision vitrectomy system and minimal illumination. Case Rep Ophthalmol. 2016;7(3):265-269. doi:10.1159/000452993

12. Ho PC, Mainster MA, Dieckert JP, et al. Fundus contact lenses for closed pars plana vitrectomy. Ophthalmol Suppl. 1983;90 (9):106-114. doi:10.1016/S0161-6420(83)34447-X 
13. Lai CT, Kung WH, Lin CJ, et al. Outcome of primary rhegmatogenous retinal detachment using microincision vitrectomy and sutureless wide-angle viewing systems. BMC Ophthalmol. 2019;19(1):230. doi:10.1186/s12886-019-1238-3

14. Inoue M. Wide-angle viewing system. Dev Ophthalmol. 2012;54:87-91.

15. Chalam KV, Shah VA. Optics of wide-angle panoramic viewing system-assisted vitreous surgery. Surv Ophthalmol. 2004;49 (4):437-445. doi:10.1016/j.survophthal.2004.04.010
16. De Oliveira PR, Burger AR, Chow DR. Vitreoretinal instruments: vitrectomy cutters, endoillumination and wide-angle viewing systems. Int J Retina Vitreous. 2016;2(1):28. doi:10.1186/s40942016-0052-9

\section{Publish your work in this journal}

Clinical Ophthalmology is an international, peer-reviewed journal covering all subspecialties within ophthalmology. Key topics include: Optometry; Visual science; Pharmacology and drug therapy in eye diseases; Basic Sciences; Primary and Secondary eye care; Patient Safety and Quality of Care Improvements. This journal is indexed on PubMed

Submit your manuscript here: https://www.dovepress.com/clinical-ophthalmology-journal
Central and CAS, and is the official journal of The Society of Clinical Ophthalmology (SCO). The manuscript management system is completely online and includes a very quick and fair peer-review system, which is all easy to use. Visit http://www.dovepress.com/ testimonials.php to read real quotes from published authors. 